\title{
SOBRE DIOSES, HÉROES Y NOVELISTAS: \\ LA REINVENCIÓN DE QUETZALCÓATL Y \\ LA REESCRITURA DE LA CONQUISTA \\ EN "EL MUNDO NUEVO" DE CARLOS FUENTES"
}

\author{
POR \\ Santiago Juan-Navarro \\ Florida International University
}

Re-inventar la historia, arrancarla de la épica y transformarla en personalidad, humor, lenguaje, mito. Fuentes, La nueva novela hispanoamericana

Desde su primera colección de cuentos, Los dias enmascarados (1954), hasta sus más recientes novelas y ensayos la obra de Fuentes ha mostrado una preocupación casi obsesiva por la reescritura de la historia. En sus obras el pasado es contemplado no como un ámbito cerrado y pasivo que aguarda investigaciones puramente arqueológicas, sino como pluridimensional, abierto, reinterpretable y vivo dentro de nuestro mundo contemporáneo. Para Fuentes el medio privilegiado para la exploración de tal pasado no es el ámbito discursivo de la historia, sino el espacio imaginativo de la novela. Su objetivo: sacar a la luz las áreas oscuras del registro histórico, o como dice el propio Fuentes, "darle una voz a los silencios de nuestra historia" ("Discurso inaugural” 13).

Terra Nostra (1975) representa el proyecto de revisión del pasado más ambicioso que Fuentes ha llevado a cabo hasta la fecha. En este inmenso retablo histórico, Fuentes reescribe una gran parte de la historia de Occidente, centrando su atención en el alborear de la Edad Moderna y en el enfrentamiento cultural entre la España imperial y el México prehispánico. Pero la característica más destacada y sorprendente de esta novela es su uso recurrente de una historia apócrifa que acaba por desplazar la visión heredada de las crónicas oficiales. En Terra Nostra la historia tradicional de las cronologías exactas, las sucesiones dinásticas, las grandes hazañas y las empresas épicas cede su lugar a una visión alternativa del pasado donde los elementos fantásticos, a veces, resultan ser reales y los aparentemente reales, a menudo, son el resultado de la imaginación del autor.

La segunda de las tres partes en que se divide la novela, "El mundo nuevo", centra su atención precisamente en el conflictivo encuentro entre la cultura judeocristiana y el mundo azteca, encuentro que Fuentes sitúa de manera fantástica bajo el reinado de Felipe II. Recordemos que si la primera parte de Terra Nostra terminaba con la llegada al Escorial del llamado "Peregrino", hijo de Felipe el Hermoso y de Celestina, toda la sección titulada "El

\footnotetext{
* Este artículo fue posible gracias al Exchange Scholar Program entre las Universidades de Columbia y Princeton. Quisiera expresar mi agradecimiento a Rolena Adorno y a Eloise Quiñones Keber por sus consejos y sugerencias acerca de la literatura colonial y la historia y mitología mesoamericanas.
} 
mundo nuevo" consiste en la relación que el Peregrino hace al Rey de su descubrimiento y conquista del nuevo continente. A diferencia de la discontinuidad narrativa que caracteriza al resto de Terra Nostra, los acontecimientos descritos en esta parte central se acomodan a una estructura cronológica bastante precisa. Sus diecinueve capítulos definen el itinerario del Peregrino desde su encuentro con Pedro en un paraje de la costa española (cap. 60), hasta México Tenochtitlan, en el corazón mismo del imperio azteca (caps. 76-77). ${ }^{1}$ Los dos últimos segmentos (78-79) narran la huida del protagonista y su reaparición en el mismo lugar desde donde había emprendido su exploración, el Cabo de los Desastres, en las costas de Galicia. En su descripción del accidentado viaje del Peregrino, Fuentes crea una vasta red de alusiones en la que se superponen, por un lado, episodios significativos de la saga de Quetzalcóatl, el rey-dios de los nahuas, y por el otro, el recorrido de Hernán Cortés en su conquista de México Tenochtitlan.

El presente trabajo estudia la reinvención del pasado en "El mundo nuevo". De entre la amplísima variedad de temas mitológicos e históricos reescritos por Fuentes en esta parte de Terra Nostra nos centraremos en la interpretación de la leyenda supuestamente prehispánica del regreso de Quetzalcóatl y en la visión de la conquista que se desprende de la novela. En un primer apartado se exponen las versiones más autorizadas del mito, así como la versión que el propio Fuentes ha consignado en su obra ensayística. Nuestro objetivo es delimitar con la máxima precisión posible el trasfondo histórico y mítico sobre el que Fuentes recrea las diferentes variantes de la leyenda en el ámbito de la ficción. La segunda parte consiste en un análisis textual de "El mundo nuevo" orientado hacia el uso que Fuentes hace del material documental existente sobre el pasado prehispánico y el periodo de la conquista. El énfasis se da a tres niveles: textos náhuatl inmediatamente posteriores a la conquista de la Nueva España; historias, crónicas y relaciones de conquistadores y misioneros; y fuentes secundarias contemporáneas a la obra de Fuentes y procedentes de la antropología cultural y la etnohistoria. Mediante el análisis de tal uso y manipulación del material documental nos proponemos desentrañar el proyecto cultural que Fuentes presenta en "El mundo nuevo" a la luz de las nuevas formas de la novela histórica (materia del tercer y último apartado).

Quetzalcóatl es una de las figuras más polifacéticas de las religiones meso-americanas. Según David Carrasco (3), su culto puede rastrearse desde, al menos, los tiempos del gran centro cultural de Teotihuacán (100-750 d.C.) hasta la caída de la capital azteca en 1521.

\footnotetext{
${ }^{1}$ En nuestra discusión del México anterior a la conquista se usarán cuatro términos (azteca, mexica, nahua y náhuatl) estrechamente relacionados, pero con un campo de aplicación específico. En "Aztecs Before and After the Conquest" (224-25), Eloise Quiñones Keber propone el uso de "azteca" para referirnos al imperio tributario dominado por México Tenochtitlan durante la época de los primeros contactos con los europeos. "Mexica", por su parte, designa más específicamente a los habitantes de las ciudades que poblaban la isla en el lago Texcoco (México Tenochtitlan y Tlatelolco). Finalmente, nahua es el término genérico con el que nos referimos a los aztecas en sus prácticas culturales y náhuatl el nombre que recibe su lengua.
} 
Para H.B. Nicholson ("Ehécatl” 35) el nombre Quetzalcóatl ("la serpiente de plumas de quetzal") se suele asociar con una doble identidad: la de un dios creador (Ehécatl Quetzalcóatl) y la de un soberano tolteca (Topiltzin Quetzalcóatl), que adoptó el nombre del dios. $^{2}$ El primero, Ehécatl, tiene un valor demiúrgico capital en las cosmogonías del México Central. De los cuatro soles o eras en que los nahuas dividían el pasado, el segundo fue gobernado por Ehécatl Quetzalcóatl, quien participó asimismo en la formación del quinto sol o era presente. El nombre Ehécatl, "viento", alude a su relación con esta fuerza natural y se le representa con una máscara bucal, a través de la cual sopló el viento de la creación (Quiñones Keber, "From Tollan" 77). Asociado con los conceptos de la creación y la fertilidad, Ehécatl Quetzalcóatl fue el dios protector del centro comercial y religioso de Cholula. Desde el punto de vista arqueológico, el culto a Ehécatl Quetzalcóatl parece extendido en el México Central, el oeste de Oaxaca y la Costa del Golfo (Nicholson, "Ehécatl" 36).

Pero además del Quetzalcóatl-dios (Ehécatl) existen numerosas referencias documentales a un soberano y sacerdote tolteca que ostentaba el título de Topiltzin ("nuestro querido señor") Quetzalcóatl. Los documentos inmediatamente posteriores a la conquista contienen transcripciones de la historia mesoamericana que hablan de esta figura cuasilegendaria que gobernó la ciudad de Tollan. ${ }^{3}$ Basándose principalmente en documentos del siglo XVI, H.B. Nicholson ha reconstruido una historia básica del mito tal y como floreció en las ciudades principales de México en el momento en que llegaron los españoles en 1519.4 Según Nicholson, Topiltzin Quetzalcóatl es un personaje histórico que existió en un periodo temprano de la historia tolteca y cuya figura habría de confundirse con la de Ehécatl Quetzalcóatl, dios antiguo de la fertilidad creador de la lluvia y el viento. Hijo de uno de los principales conquistadores toltecas, Topiltzin vengó la muerte de su padre y se alzó como líder secular y sacerdotal de un grupo de Tollan. Durante su reinado innovó numerosos aspectos religiosos y culturales, lo que habría de provocar un conflicto que acabó con el abandono de Tollan por parte de Topiltzin y sus seguidores. ${ }^{5}$ Dirigiéndose siempre

\footnotetext{
${ }^{2}$ Esta costumbre tolteco-azteca de ostentar el nombre del dios como título ha dado lugar a un sinfin de confusiones que han afectado tanto a la evolución de la leyenda en manos indígenas como a las recopilaciones que de ella hicieron los historiadores modernos. Así, en las descripciones del héroe histórico no es extraño encontrar, a menudo, los diferentes conceptos asociados a Quetzalcóatl-dios (Quiñones Keber, "The Aztec Image" 337).

${ }^{3}$ La legendaria ciudad de Tollan ha sido identificada con el yacimiento arqueológico de Tula en el Estado de Hidalgo, el cual alcanzó su esplendor del 900 al 1200 d.C. (Quiñones Keber, "The Aztec Image" 337).

${ }^{4}$ Los seis documentos que forman el corpus central del ensayo de Nicholson son: Historia de los Mexicanos por sus Pinturas (c. 1531-1537), las Relaciones de Juan Cano (Relación de la genealogía $y$ linaje de los Señores que han señoreado esta tierra de la Nueva España y Origen de los Mexicanos) (c. 1532), Histoyre du Mechique (c. 1535-1543), Leyenda de los soles (c. 1558), Historia General de las Cosas de Nueva España (c. 1547-1585) de Fray Bernardino de Sahagún, y Anales de Cuauhtitlan (c. 1570). Estos documentos ofrecen la narrativa más completa sobre Quetzalcóatl. Para un análisis detallado del mito de Quetzalcóatl en estas fuentes véase Nicholson ("Topiltzin"). Werner Stenzel ofrece un resumen de fuentes similares desde una perspectiva más escéptica.

${ }^{5}$ Una de las reformas religiosas introducidas supuestamente por Quetzalcóatl fue el autosacrificio consistente en punciones con espinas. Varios documentos del siglo XVI (Códice Vaticano Latino,
} 
hacia el este, tras una larga estancia en Cholula, desapareció más allá del horizonte conocido. Junto al valor de sus innovaciones en el ámbito de la religión y la cultura, los documentos analizados por Nicholson revelan la importancia de Topiltzin Quetzalcóatl como líder político y legitimador de la las dinastías guatemaltecas de origen tolteca (Nicholson, "Topiltzin" 360-61; "Ehécatl" 38-39).

La figura mixta de un Quetzalcóatl héroe-dios está íntimamente relacionada con el fenómeno de la conquista, o al menos con muchas de las versiones que de la misma han llegado hasta nosotros. Desde el mismo siglo XVI se barajaron diversas hipótesis para explicar la rápida conquista de todo un imperio por un grupo reducido de españoles. Una de las más populares fue, y sigue siendo, el miedo paralizante que los presagios y profecías ejercieron sobre el pueblo azteca y, especialmente, sobre su soberano. De acuerdo con tales profecías, Quetzalcóatl habría de regresar para reclamar su trono en una fecha determinada (el año 1 Caña del calendario nahua). El desembarco de los españoles en las costas del Golfo de México coincidió aparentemente con el momento anunciado.

Un problema que, sin embargo, debemos tener siempre en cuenta al tratar temas relacionados con los mitos nahuas es la ausencia de una literatura escrita anterior a la conquista y la falta de elementos de juicio que permitan aseverar la fiabilidad de muchos de los documentos a nuestro alcance. Los primeros intentos de sistematización de la mitología nahua, tanto por parte indígena como española, se acometieron en las décadas siguientes a la caída del imperio azteca. Este hecho, unido al proceso de intercambio cultural que resultó de la conquista y a los numerosos intereses que estaban en juego en esos momentos, dio lugar a versiones del mundo indígena muy diferentes y, en ocasiones, contradictorias. En relación con la figura mítica de Quetzalcóatl ha surgido en los últimos años una corriente crítica que cuestiona abiertamente la naturaleza prehispánica de algunas partes importantes del mito. En concreto, investigadores como Victor Frankl (1963), J.H. Elliott (1967), Jacques Lafaye (1976), Anthony Pagden (1986), Susan D. Gillespie (1989) y Werner Stenzel (1991) ponen en entredicho el valor decisivo (e incluso la autenticidad) de las profecías en la conquista de la Nueva España. Lafaye, Pagden y Elliott, por ejemplo, sugieren la naturaleza apócrifa de los dos discursos de Moctezuma que Cortés "reproduce" en sus Cartas de relación, y en los que el soberano azteca reconoce en Cortés a un dios profetizado. La importancia de este hecho es clave porque, como señala Lafaye (Quetzalcóatl 150), la relación de Cortés es el documento más importante de que se valió Gómara, quien a su vez se convirtió en la fuente más influyente de los historiadores del siglo XVII. Para Lafaye, las versiones que sobre el mito de Quetzalcóatl han llegado hasta nosotros no tienen su origen exclusivamente en el mundo prehispánico, sino que son el resultado del sincretismo religioso y cultural que tuvo lugar en la Nueva España durante el siglo XVI. Al pensamiento apocalíptico indígena se sumó el mesianismo de la civilización judeocristiana, y ambas tradiciones, según Lafaye, buscaron en el mito de Quetzalcóatl una forma de liberarse "from a situation that their religious conscience found intolerable, the situation of living a moment of history - and henceforth to be their common history - not foreseen by their respective prophets"

Códice Telleriano-Remensis y Anales de Cuauhtitlan), aluden a esta representación de Quetzalcóatl como penitente. Para un examen detallado de este aspecto de la personalidad de Topiltzin Quetzalcóatl véase Alfredo López Austin (Hombre-Dios 143-60). 
(Quetzalcóatl 153). Desde el punto de vista de Pagden, Elliott, Frankl, Gillespie y Stenzel, la manipulación de Cortés se explicaría como un intento de legitimar la empresa conquistadora y de congraciarse con un rey que nunca le había autorizado a hablar por él. ${ }^{6}$ Así, el encuentro de Cortés con Moctezuma es presentado en los términos de la tradición política y judicial de la España del siglo XVI: el vasallo, en este caso Moctezuma, da la bienvenida a su "señor natural", Cortés, quien a su vez se describe a sí mismo como embajador del rey (Pagden 467; Gillespie 181). Pero si en las Cartas de Cortés no hay ninguna alusión directa a Quetzalcóatl, tal conexión se produce en los escritos de los franciscanos Motolinía y Sahagún. Elliott ha subrayado la influencia de las tradiciones apocalípticas sobre los misioneros franciscanos, quienes habrían llegado al Nuevo Mundo con la esperanza utópica de fundar una nueva Iglesia, lejos de la corrupción eclesiástica que prevalecía en Europa. Cabría la posibilidad, según Elliott, de que Motolinía y Sahagún, en primer lugar, y otros misioneros después, hubieran agigantado el valor de los presagios y las profecías como manifestaciones de su propio plan providencialista. En resumen, las múltiples versiones de la leyenda favorecieron intereses particulares que podrían sintetizarse en un interés por legitimar y justificar las actitudes adoptadas en el momento de la conquista, tanto por parte de los aztecas como por parte de los conquistadores.

La versión que Fuentes nos ofrece de la saga del héroe-dios no muestra, sin embargo, escepticismo alguno. Como cabría esperar de un novelista, su retrato de Quetzalcóatl magnifica los rasgos más espectaculares y literarios del mito. En The Buried Mirror (1992), una de sus obras más recientes, Fuentes presenta un Quetzalcóatl en el que se entremezclan los rasgos del dios y los del soberano-sacerdote de Tollan, así como las numerosas y contradictorias narrativas que han llegado hasta nosotros. Para Fuentes, Quetzalcóatl, la Serpiente Emplumada, fue el creador de la humanidad, de la agricultura, de la vida en sociedad, el descubridor del maíz e inventor de la arquitectura, la canción, la escritura, la minería y la orfebrería; aquél que dio a los hombres sus herramientas y les enseñó a trabajar el jade y las plumas y a plantar el maíz. Por el número de sus enseñanzas, Quetzalcóatl llegó a ser identificado con Toltecayotl, palabra que significa "Totalidad de la Creación" (Espejo 107). Su valor moral en la antigua Mesoamérica le lleva a Fuentes a equipararlo con la figura de Prometeo:

Quetzalcóatl se convirtió en el héroe moral de la antigüedad mesoamericana, de la misma manera que Prometeo fue el héroe del tiempo antiguo de la civilización mediterránea, su libertador, aun a costa de su propia libertad. En el caso de Quetzalcóatl, la libertad que trajo

\footnotetext{
${ }^{6}$ Pagden y Elliott van mas lejos que Lafaye al señalar que no existen evidencias de una tradición prehispánica sobre la leyenda de un hipotético regreso de Quetzalcóatl para reclamar su trono. Ambos, sin embargo, omiten un hecho importante que apuntábamos anteriormente: el carácter eminentemente oral de la cultura nahua que ha impedido que lleguen a nuestro conocimiento relatos consistentes acerca de su historia y mitología. Lo que sí existen son evidencias arqueológicas que muestran la extensión del culto a Quetzalcóatl por la mayor parte de Mesoamérica (Carrasco 50-55) y que contradicen la visión restrictiva del mito que propone Pagden (467-69). Para un estudio detallado del papel de las profecías en la caída del imperio azteca véanse Nicholson ("Topiltzin") y Carrasco.
} 
al mundo fue la luz de la educación. Una luz tan poderosa que se convirtió en la base de legitimidad para cualquier Estado, que aspirase a suceder a los toltecas, heredando su legado cultural (Espejo 107).

Aunque la visión de Fuentes es muy inclusiva, el novelista mexicano tiende a favorecer determinados aspectos de la figura de Quetzalcóatl. Por ejemplo, se subraya el valor de Quetzalcóatl como demiurgo y héroe cultural por encima de los atributos militares que también caracterizaban a Topiltzin Quetzalcóatl.

En el prólogo a una de las ediciones de Todos los gatos son pardos (1980), drama épico sobre la conquista, Fuentes ofrece una descripción de la caída del dios-héroe que desarrollará en sus obras de ficción, especialmente en Terra Nostra. ${ }^{7}$ El prólogo comienza así:

\begin{abstract}
Cuéntase en los anales de Cuautitlán que los llamados Tezcatlipoca, Ilhuimécatl y Toltécatl (todos ellos mágicos certificados) decidieron expulsar de la ciudad de los dioses a Quetzalcóatl, la serpiente emplumada, el creador de los hombres y el instructor en las artes básicas: el cultivo del maíz, el pulimento del jade, la pintura del mosaico y el tejido y tintura del algodón. Pero necesitaban un pretexto: la caída. Pues mientras representase el más alto valor moral del universo indígena, Quetzalcóatl era intocable. Prepararon pulque para emborracharlo, hacerle perder el conocimiento e inducirlo a acostarse con su hermana, Quetzaltépatl (1153).
\end{abstract}

Sin embargo, los magos no encontraron la forma de doblegar la integridad moral de Quetzalcóatl. Fue Tezcatlipoca, el "espejo humeante", quien ideó el plan definitivo: llevarle a Quetzalcóatl un espejo que le mostrara su propio cuerpo. Al ser un dios, Quetzalcóatl desconocía su apariencia, creía no tener rostro. Al verlo reflejado en el espejo, la serpiente de plumas sintió terror y vergüenza. Enajenado ante una imagen humana (no divina) que creía intolerable esa misma noche bebió y cometió incesto con su propia hermana. Al día siguiente se marchó hacia Levante, hacia el mar, diciendo que "el Sol lo llamaba" y prometiendo regresar. Fuentes acaba su versión "libre" del mito diciendo: "Quetzalcóatl se fue sin saber que había sido el protagonista simultáneo de la creación y de la caída. Sembró, en la tierra, el maíz; pero en las almas de los mexicanos sembró una infinita sospecha circular" (Todos los gatos 1154; Tiempo mexicano 17).

Esta versión del mito de la caída de Quetzalcóatl muestra el eclecticismo amalgamante de la escritura de Fuentes. Aunque su versión dice basarse en los Anales de Cuauhtitlan, la descripción de la huida del héroe no se corresponde con la de esta fuente, sino con la del final alternativo que propone Sahagún en su Historia General. Si en los Anales Quetzalcóatl se sacrifica prendiéndose fuego a sí mismo, en la Historia General de Sahagún el héroe huye

\footnotetext{
${ }^{7}$ Una parte substancial de dicho prólogo aparece en forma de artículo en la colección de ensayos Tiempo mexicano (1971). Todos los gatos, por su parte, ha sido también objeto de revisión, apareciendo recientemente bajo el título de Ceremonias del alba (1991). Un cambio importante en esta nueva reescritura lo constituye la inclusión de la caída de Quetzalcóatl dentro del propio texto de la obra. En los momentos iniciales del drama, Doña Marina ("la Malinche") narra este episodio, subrayando, así, la importancia de la leyenda y su influencia en los avatares de la conquista.
} 
hacia Levante en una barcaza de serpientes, prometiendo regresar. ${ }^{8}$ Incluso los detalles de la descripción de la caída que hace Fuentes se apartan libremente de la supuesta fuente original. En los Anales no se menciona o sugiere que el horror de Quetzalcóatl al contemplarse en el espejo se deba a razones metafísicas sino a la monstruosa deformación de su anciano rostro. ${ }^{9}$ Una simple revisión del pasaje en los Anales deja ver sus diferencias en relación con la versión de Fuentes:

Y al momento se vio Quetzalcóatl: se llenó de pavor, dijo:

- iSi mis vasallos me vieran a correr echarían!

Porque sus párpados estaban muy inflamados, hundidos los ojos en las cuencas, y la cara por doquiera toda llena de abolsamientos, ino tenía figura humana! Cuando vio el espejo dijo: - ¡Nunca me verán mis siervos aquí he de estarme solo! [el subrayado es mío] (Garibay, Historia I:310-11)

Tampoco contemplan los Anales que la caída se produzca de forma tan mecánica como en la explicación de Fuentes. Aterrorizado por la fealdad de su semblante, Topiltzin Quetzalcóatl decide recluirse en su palacio de Tollan, lejos de las miradas de su pueblo. Es sólo después de un tercer engaño (perpetrado esta vez por Ihuimécatl y Toltécatl, no por Tezcatlipoca) y de sucesivas negativas, cuando Quetzalcóatl accede a probar la bebida, embriagándose finalmente con su hermana. Incluso el episodio del incesto sobre el que Fuentes vuelve recurrentemente en sus reinvenciones del mito, es presentado en los Anales de forma muy sutil. Una de las supuestas evidencias vendría dada por estos versos de contenido lirismo:

Y después de embriagarse, ya no dijeron:

¡Si nosotros somos ascetas! Y no bajaron ya nunca

\footnotetext{
${ }^{8}$ Sahagún describe la huida de Quetzalcóatl en estos términos: "Y así, en llegando a la ribera de la mar, mandó hazer una balsa de culebras que se llama coatlapechtli, y en ella entró y asentóse como en una canoa, y así se fue por la mar navegando, y no se sabe cómo y de qué manera llegó al dicho Tlapallan" (I:291). La profecía del retorno del dios es mencionada, asimismo, en el cap. 7, libro VIII (II:293) y en el capítulo 2, libro XII (IV:25) de la Historia General.

${ }^{9}$ Como hemos visto, en Todos los gatos (1154) y en Tiempo mexicano (17), Fuentes atribuye el horror de Quetzal cóatl a que éste "desconocía la existencia de su apariencia". En El espejo enterrado Fuentes lleva esta interpretación personal todavía más lejos: "Creía que, siendo un dios, carecía de rostro. Ahora, reflejado en el espejo enterrado, vio su propio rostro. Era, después de todo, la cara de un hombre, la cara de la criatura del dios. Así, Quetzalcóatl se dio cuenta de que al tener un rostro humano, debía, también, tener un destino humano" (116). La misma explicación puede encontrarse en su obra dramática Ceremonias del alba, donde, en el momento en que Quetzalcóatl grita de terror, Tezcatlipoca pronuncia estas palabras: "Reconócete en un rostro humano, oh Gran Dios, y teme poseer también un destino humano ....” (15). Pero, el terror de Topiltzin Quetzalcóatl se debe, según los Anales, a una razón contraria a la aducida por Fuentes, es decir, al carácter inhumano (por su deformidad) del rostro de Quetzalcóatl.
} 
al baño ritual al río, ni tampoco se punzaron con espinas, ni nada hicieron cuando la aurora aparece. (Garibay, Historia $\mathrm{I}: 313)^{10}$

Después de un largo peregrinar Quetzalcóatl llega a la playa donde, en un acto de inmolación final se prende fuego a sí mismo. Aves de bello plumaje acuden a contemplar sus cenizas y su corazón asciende finalmente al cielo transformado en el planeta Venus (Garibay, Historia I:317).

De acuerdo con la versión del mito que Fuentes ofrece en El espejo enterrado, Quetzalcóatl habría anunciado que regresaría, y que lo haría en un momento determinado: Ce Acatl, el año 1 Caña dentro del calendario indígena (116). La llegada de los españoles bajo el mando de Cortés el Jueves Santo de 1519 coincidió con el momento profetizado, de ahí que Moctezuma asociara la llegada del conquistador con el regreso del dios. De acuerdo con Fuentes, la venida de los conquistadores fue precedida de presagios sobrenaturales. Signos en el firmamento, catástrofes naturales y toda suerte de fenómenos extraños. En todo el imperio azteca se sabía que la profecía estaba a punto de cumplirse: Quetzalcóatl iba a regresar. El tiempo del quinto sol se aproximaba a su fin. Cuando Moctezuma recibió la noticia de que fortalezas flotantes se aproximaban por el este y que de ellas descendían hombres blancos barbados vestidos de oro y plata sobre el lomo de bestias desconocidas, supo que el fin era inevitable (El espejo 116).

De entre las fuentes documentales del siglo XVI que Nicholson considera más completas y fidedignas, sólo una contempla abiertamente la profecía del regreso de Quetzalcóatl, así como los portentos de que habla Fuentes: la Historia General de Sahagún. ${ }^{1}$ De acuerdo con el testimonio de los informantes indígenas que ayudaron a Sahagún, diez años antes de la llegada de los españoles empezaron a sucederse una larga serie de presagios funestos. Sahagún especifica ocho de ellos: 1) una inmensa llama de fuego ardió durante un año; 2) el templo de Huitzilopochtli se incendió repentinamente; 3) el templo de Xiuhtecutli fue alcanzado por un rayo, sin que se escuchara trueno alguno; 4) un gran cometa surcó el firmamento dividiéndose en tres; 5) hirvieron las aguas del lago socavando los cimientos de las casas; 6 ) por la noche una mujer recorrió las calles de la ciudad llorando por el futuro de sus hijos; 7) unos pescadores recogieron de las aguas del lago un extraño pájaro con un espejo en la cabeza; 8) se vieron "hombres deformes" "y "seres

\footnotetext{
${ }^{10}$ La representación indirecta y poética del supuesto incesto en los Anales contrasta con la cruda reconstrucción de Fuentes en Tiempo mexicano (17) y El espejo enterrado (116), donde usa el verbo "fornicar" (derivado de "fornix", prostíbulo) para expresar la transgresión sexual de los hermanos, asi como en Terra Nostra y Ceremonias del alba, donde tal acto es descrito como una violación.

"En los Anales de Cuauhtitlan, si bien se enumeran toda una serie de desastres que suceden a la muerte y resurrección del soberano y que culminan con la destrucción total de Tollan, no hay rastro de tales presagios, ni de un anuncio profético como el que presenta el novelista. La mayor parte de las referencias a la leyenda del regreso de Quetzalcóatl provienen o bien de fuentes en donde es difícil decir donde acaba el relato propiamente indígena y donde empieza el discurso evangelizador, o bien de autores que usaron las Cartas de Cortés como base de sus crónicas. Entre las versiones pertenecientes al primer grupo pueden consultarse las de Fray Toribio de Benavente (Motolinía) (Memoriales 60, 83; Historia 176), Fray Diego Durán (II: 507, 514, 541), y Fray Gerónimo de Mendieta (93). Para ejemplos del segundo grupo, véase Francisco López de Gómara (II: 47).
} 
monstruosos" (Sahagún 1956, IV:23-24). Fuentes reproduce estos portentos literalmente en Todos los gatos son pardos, Terra Nostra, Ceremonias del alba y El espejo enterrado. La influencia que, según Fuentes, tuvieron los presagios y profecías sobre los intercambios entre conquistadores y aztecas parece igualmente sacada de la Historia General de Sahagún, donde Moctezuma recibe a Cortés como el "esperado", cediendóle su trono con las mismas palabras que Fuentes reproducirá en sus obras: "Señor nuestro: te has fatigado, te has dado cansancio: ya a la tierra tú has llegado. Has arribado a tu ciudad: México. Aquí has venido a sentarte en tu solio, en tu trono. Oh, por tiempo breve te lo reservaron, te lo conservaron, los que ya se fueron, tus sustitutos" (León-Portilla La visión 67). ${ }^{12}$ Según la versión de Sahagún, los aztecas descubrieron finalmente la naturaleza real de los españoles y todavía en los tiempos de Sahagún esperaban el futuro regreso del verdadero Quetzalcóatl.

Hay muchos otros elementos que permiten hacer de la Historia General de Sahagún una de las fuentes principales del novelista mexicano, tanto en su elaboración general del mito de Quetzalcóatl, como en la visión del mundo prehispánico y de la conquista que se desprende de Terra Nostra. Fuentes comparte además con los pensadores franciscanos la búsqueda de una síntesis entre pensamiento utópico y apocalíptico. ${ }^{13}$ En cualquier caso, es necesario tener en cuenta que la concepción de la historia que Fuentes presenta en su obra es siempre profundamente personal. Su manipulación de las fuentes sobre la historia de la conquista y el mito de Quetzalcóatl, si bien es moderada en sus ensayos, alcanza su expresión más original en Terra Nostra, donde se propone abiertamente una reescritura de las tradiciones indígena y cristiana. Fuentes se vale de gran número de versiones que le permiten ofrecer una gran síntesis detrás de la cual se perfila su proyecto cultural: la creación de toda una mitología del mestizaje y la presentación del intelectual como abanderado del cambio cultural y político en Latinoamérica.

"El mundo nuevo" es el título que recibe la segunda de las tres partes en que aparece dividida Terra Nostra. En esta parte el Peregrino cuenta al rey su viaje a tierras de Mesoamérica. Dos motivos se entrecruzan en su relato, formando un doble eje estructurador: la saga de Quetzalcóatl y el "descubrimiento" y conquista de América. Tanto el componente mítico como el histórico son sometidos por Fuentes a un proceso de selección y distorsión

\footnotetext{
${ }^{12}$ Cito aquí la versión de León-Portilla, por ser la que Fuentes reproduce literalmente en "El mundo nuevo".

${ }^{13}$ Como hemos visto que sugería Elliott, los franciscanos querían salir de la condición degradada en la que se encontraba la cristiandad en el siglo XVI, mediante la creación en el Nuevo Mundo de una nueva Iglesia que materializara las profecías de la Revelación ("The Mental World" 54-55). Para un estudio detallado de la visión apocalíptica de los misioneros franciscanos, véase Phelan, The Millennial Kingdom. Igualmente, Fuentes concibe el Nuevo Mundo como espacio de ensayos utópicos lejos de la corrupción de Europa. En Cervantes (89), Valiente mundo (64-66) y El espejo enterrado (144-45), el novelista mexicano discute ampliamente las conexiones entre los frailes humanistas que viajaron al Nuevo Mundo y el pensamiento utópico del Renacimiento. La relación de Fuentes con el pensamiento apocalíptico ha sido estudiada por Parkinson-Zamora en Writing the Apocalypse (148-75).
} 
que da lugar a un universo original donde el autor mexicano dramatiza su visión del traumático encuentro entre dos civilizaciones. La forma misma en que Fuentes aglutina versiones diversas del pasado evoca la descripción que Lévi-Strauss hace del narrador de mitos tradicional, al que se refiere significativamente con el nombre de bricoleur (27-29). Como el bricoleur, Fuentes es no tanto un inventor de historias como un organizador y compilador de versiones y conceptos preexistentes en las tradiciones mítica e historiográfica de Mesoamérica. Con el propósito de explicar los problemas que enfrenta la comunidad hispanoamericana en el momento presente, Fuentes se remonta a través de la experiencia colectiva y reorganiza los elementos a su alcanze dentro de un nuevo sistema interpretativo que aparece revestido del poder legitimador del mito. A continuación analizaremos el tratamiento y evolución de la figura de Quetzalcóatl dentro del texto de Fuentes y su articulación con la historia de la conquista. Los avatares del Peregrino en el Nuevo Mundo se corresponden, por un lado, con las etapas principales de la vida de Topiltzin Quetzalcóatl y, por otro, con momentos significativos en la conquista de América. El estudio de estos dos componentes se llevará a cabo en estrecha relación con las fuentes documentales de la novela.

En los tres primeros capítulos (60-63) el Peregrino describe su viaje de descubrimiento junto a Pedro, viaje que empieza bajo el signo de Venus, una de las manifestaciones de Quetzalcóatl. ${ }^{14}$ La formación del intertexto mítico nahua en esta primera fase, sin embargo, sólo podemos detectarla a posteriori, después de una atenta lectura de los nueve primeros capítulos. En estos momentos iniciales de "El mundo nuevo" predominan las referencias intertextuales a los diarios, cartas, relaciones y crónicas del descubrimiento y la conquista. La narración de la travesía, por ejemplo, evoca a menudo la descripción del primer viaje que hacen Cristóbal Colón en sus Diarios y Hernando Colón en Historia del Almirante. La misma relación entre Pedro y el Peregrino reproduce las tensiones entre el almirante y los marinos de aquella expedición. En los tres capítulos siguientes (63-65) se narra la llegada a la Costa de las Perlas y la vida de ambos, en un lugar descrito como "una perdida ribera de la Creación" (380). Las primeras representaciones de este "mundo nuevo" se corresponden con los comentarios de Colón, Américo Vespucio, Pedro Mártir de Anglería y Pérez de Oliva acerca de una utópica "Edad de Oro" en el recién hallado continente. ${ }^{15}$ Por lo que se refiere a los pasos iniciales de los dos personajes en la costa, éstos repiten (a veces literalmente) algunos momentos de la historia del naufragio de Pedro Serrano, incluida en los Comentarios reales del Inca Garcilaso. ${ }^{16}$ El capítulo 66, "El trueque", presenta el primer encuentro con los nativos del continente, en el cual muere Pedro y sobrevive el Peregrino gracias a su participación en las reglas del intercambio y la negociación que gobiernan la vida de los indígenas. El comportamiento del Peregrino en este episodio, así como su

${ }^{14} \mathrm{El}$ propio nombre del Peregrino remite a la condición de auto-exiliado de Quetzalcóatl, cuyo peregrinaje a Tlapallan, "la ciudad del sol", es recogido por numerosas fuentes. Véanse, por ejemplo, los caps. 12-14 del libro III de la Historia General de Sahagún (I:288-91).

${ }^{15}$ Véanse Colón, "Diario del primer viaje", en Textos (15-138); Américo Vespucio, El nuevo mundo; Pedro Mártir de Anglería, Décadas del Nuevo Mundo; y Hernán Pérez de Oliva, Historia de la Invención de las Indias.

${ }^{16}$ Compárese el segmento 63 de Terra Nostra ("Más allá") con el cuento interpolado por el Inca en el cap. 8, libro I de sus Comentarios (18-20). 
posterior integración en la comunidad india y ulterior transformación en líder mesiánico nos llevaría a considerar los Naufragios de Cabeza de Vaca como otro posible intertexto. Por otro lado, la relación que el Peregrino hace de esta comunidad utópica, nos remite a las "utopías anarquistas" que, según Fuentes, recrearon algunos de los primeros exploradores del Nuevo Mundo. ${ }^{17}$

El dominio del intertexto mítico prehispánico sólo se produce a partir del encuentro del Peregrino con el llamado anciano de las memorias. En el espacio sagrado de un templo, el Peregrino es iniciado en los misterios de la cosmovisión nahua por un viejo de edad inmemorial que conserva las dos riquezas de la comunidad: los tesoros de las perlas y el maíz y la memoria de los mitos del origen. En el capítulo 69, "La leyenda del anciano", el viejo ofrece al Peregrino una reconstrucción de la cosmogonía de los nahuas, centrándose en la creación de la tierra, del hombre y del sol. De acuerdo con el anciano, la tierra fue creada por mediación de dos dioses, quienes al romper los miembros de una diosa dieron lugar al nacimiento de todas las cosas. Pero al ver la diosa que los frutos nacidos de su piel crecían y se marchitaban sin provecho, convocó a otros tres dioses (uno rojo, otro blanco y un tercero negro) para que, del sacrificio de uno de ellos pudieran nacer los seres humanos. Sólo el dios negro, jorobado y leproso, se arrojó al vientre en llamas de la diosa, de donde surgieron los hombres. De las entrañas humeantes de la diosa nació asimismo una columna de fuego, el fantasma del dios jorobado, que ascendió al cielo, convirtiéndose en el primer sol de los hombres.

Aunque el anciano no menciona directamente a Quetzalcóatl, su cosmovisión se basa en diferentes versiones del mito de la creación en las cuales Quetzalcóatl juega un papel crucial. La primera parte de la relación del anciano coincide en líneas generales con uno de los mitos de la creación recogidas por Garibay, en el que los protagonistas son Quetzalcóatl y Tezcatlipoca (Garibay, Épica 3-5). ${ }^{18}$ La segunda parte se basa en el mito del origen del quinto sol. Según el texto nahua del Códice Matritense el quinto sol fue el resultado del

\footnotetext{
${ }^{17}$ Fuentes recoge en este sentido los comentarios de Américo Vespucio en Mundus Novus (1503). Los grupos indígenas que Vespucio describe en su obra vivían en armonía con la naturaleza, sin concepto alguno de propiedad y sin necesidad de gobierno o autoridad (Fuentes, Buried Mirror 133-34). En The Old World and the New (25-27), J.H. Elliott ha señalado asimismo como los descubrimientos movieron a los pensadores del Renacimiento a cuestionar valores fundamentales de la civilización europea y a proyectar sobre América un cuadro idílico en el que poder hacer realidad sus sueños. Recordemos que poco después de darse a conocer los escritos de Vespucio, Tomás Moro publicó su Utopia (1516) y que, en las décadas siguientes, franciscanos y jesuitas intentaron llevar a la práctica en América las ideas de Moro. Para un estudio de la influencia de los informes de Colón y Vespucio en la formación del pensamiento utópico humanista, véanse Charles L. Sanford (56-73) y J. Martin Evans (2-12). El impacto del utopismo en la cultura hispanoamericana ha sido igualmente estudiado por Fernando Ainsa, Eugenio Imaz, Frederic W. Murray y el propio Fuentes (Valiente mundo 50-71). ${ }^{18}$ Un detalle que prueba esta hipótesis es que, en la versión recogida por Garibay, Tezcatlipoca pierde un pie en su forcejeo con la diosa de la tierra, y cuando el Peregrino se encuentra con MoctezumaTezcatlipoca, éste es descrito como cojo (la novela dice que "perdió un pie el día mismo de la creación", 462). Véase también el capítulo titulado "El espejo humeante", en el que el propio Peregrino asume los atributos de Tezcatlipoca (426-44). Para diversas variantes de este mito, véanse Diego Munoz Camargo (150), M. Edouard de Jonghe (28 et seq.) y Andrés de Olmos (25 et seq.).
} 
sacrificio del dios Nanahuatzin, "el Buboso", un dios deforme que, tras arrojarse a un fuego, se convirtió en el sol. ${ }^{19}$ Como ha señalado León-Portilla, esta versión de la creación del quinto sol es de extraordinaria importancia porque explica una de las formas del misticismo nahua: "por el sacrificio existen el sol y la vida; sólo por el sacrificio podrán conservarse" (León-Portilla 1984: 61).

A la historia de la creación de la tierra, de los hombres y del sol sigue, en la relación del anciano, la de la invención y ordenación del tiempo. El viejo explica al Peregrino el calendario azteca, la concepción cíclica del tiempo y el nacimiento y muerte de los soles o eras en que los nahuas dividían la historia desde la primera creación del mundo. Una diferencia importante con respecto al modelo nahua vendría dada por el hecho de que Fuentes emplaza los hechos que relata el Peregrino en el cuarto sol, en vísperas del cataclismo que dará lugar a una nueva era. La novela subraya así el significado apocalíptico que la conquista tendría para la civilización azteca, ya que implicaría su destrucción. La forma en que el anciano narra la muerte del cuarto sol es similar a la forma en que se describen en la novela el lado catastrófico de la conquista: "El cuarto sol, que es el de la tierra, y que desaparecerá en medio de terremotos, hambre, destrucción, guerra y muerte" (400).

Al final de su parlamento el anciano se presenta a sí mismo como "el que recuerda", el guardián "del libro del destino" y de la memoria (402). Aunque no existe ninguna deidad mesoamericana que ostente literalmente tales atributos, algunos de los rasgos y funciones de este personaje evocan consistentemente la figura del arquetípico sabio y filósofo de los nahuas. Basándose en los manuscritos principales de Sahagún (Historia General y Códice Matritense), León Portilla discute la importancia que en la sociedad nahua tenía el tlamatini ("el que sabe cosas"). Algunos rasgos que dicha sociedad atribuía a los sabios o filósofos tienen su correlación en la representación que Fuentes hace del anciano de las memorias. Como el personaje de Fuentes, el tlamatini reunía las funciones de maestro, psicólogo, moralista, cosmólogo, metafísico y humanista. ${ }^{20}$ Esta figura compendiadora de la cultura nahua es retomada por Fuentes en su novela. El anciano de las memorias representa un motivo de primera magnitud en Terra Nostra. La memoria no sólo individual, sino también

\footnotetext{
${ }^{19}$ Adviértase que de nuevo nos encontramos con un documento sahaguntino como intertexto de "El mundo nuevo". El Códice Matritense fue redactado por Sahagún sobre la base de informes nativos en torno al año 1564. El mito de la creación del quinto sol puede encontrarse, también, en el libro VII de la Historia General.

${ }^{20}$ El poder magisterial del tlamatini resultaba de su conocimiento y habilidad para transmitir la verdad. De acuerdo con Sahagún, "Suya es la sabiduría transmitida, él es quien la enseña, sigue la verdad" (citado en León Portilla, La filosofía 72). Sus dotes de psicólogo emanaban de su capacidad para enriquecer la personalidad humana: "Hace a los otros tomar una cara (una personalidad), los hace desarrollarla" (74). Su función moralista residía en su influencia sobre las conductas ajenas: "pone un espejo delante de los otros, los hace cuerdos y cuidadosos" (78). El sabio nahua era el único mortal que conocía los secretos del origen y del mundo sobrenatural: "conoce lo (que está) sobre nosotros (y), la región de los muertos" (77). Era también un "investigador del mundo físico" al que iluminaba con su saber: "Aplica su luz sobre el mundo" (76) y "estudia lo que nos sobrepasa" (78). Por último, según la lectura que León Portilla hace del Códice Matritense, el tlamatini encarnaba al humanista: "gracias a él, la gente humaniza su querer y recibe una estricta enseñanza" (77).
} 
colectiva, es la fuerza que pone en movimiento la reescritura del pasado en esta novela. Magnificando aún más la representación idealizada del tlamatini, el anciano de Fuentes tiene un poder visionario que le permite percibir desde el primer instante del origen hasta el último de los secretos del porvenir. De ahí que la figura de este personaje emblemático enmarque los avatares del Peregrino en tierras mexicanas y alcance una dimensión casi profética. Es el primero en darle la bienvenida y reaparece justo al final de su viaje en la plaza de Tlatelolco, para despedirlo en su regreso a España. Todos los pasos del Peregrino dentro el mundo azteca están comprendidos entre estas dos apariciones del anciano.

La estructura del deambular del Peregrino por el Nuevo Mundo se corresponde al arquetipo de los viajes iniciáticos en los que el héroe tiene que superar una serie de pruebas antes de llegar a alcanzar el fin deseado. Un esquema análogo se desprende de las ceremonias funerarias comunes entre los nahuas. Según Séjourné, durante cuatro años el difunto debía completar con éxito siete difíciles pruebas. La última de éstas consistía en su enfrentamiento con el temido dios de los muertos, al cual se llegaba sólo tras burlar sus engaños. Séjourné relaciona varias de estas pruebas con diferentes etapas de la vida de Quetzalcóatl después de abandonar Tollan. Tanto en la narración de esta fase de Quetzalcóatl como en los ritos funerarios que, según Séjourné, la rememoraban, se representaba el pasaje del hombre hacia más altas esferas de espiritualidad que culminaría en su unión con lo trascendente (66).

A lo largo de su errático viaje, el Peregrino se enfrenta también a una serie de pruebas que supera gracias a su ingenio. En la primera de ellas se ve atrapado en un remolino del que consigue escapar tras una cuidadosa observación de los movimientos del mismo. Otra prueba le enfrenta a un grupo indígena (el Pueblo de la Selva) en las costas del Nuevo Mundo, y en esta ocasión salva la vida gracias a su ofrenda personal (unas tijeras, a cambio de las cuales recibe oro). Al exigirle el anciano de la memoria una nueva ofrenda (supuestamente su propio corazón), el Peregrino le muestra un espejo. En un episodio posterior el Peregrino es arrojado a un cenote sacrificial de donde resurgirá gracias a su hábil manipulación de los canales de agua subterráneos (aunque a la vista de los indios tal reaparición tiene una explicación sobrenatural). Internado en el bosque, se encuentra con un monstruoso leñador (por un comentario posterior sabremos que se trata de una de las numerosas encarnaciones de Tezcatlipoca) que le desafía a que tome en sus manos su corazón palpitante, cosa que el Peregrino hace venciendo su repugnancia. En una nueva prueba la llamada "señora de las mariposas" (síntesis de Tlazoltéotl e Itzpapalotl) le ofrece dos posibilidades antes de morir: disfrutar de un año de placer o seguir su errático vagabundeo. El Peregrino elige la última de estas alternativas, escapando así de lo que en realidad era una muerte inmediata. ${ }^{21}$

Tras la felizsuperación de todas estos ejercicios preparatorios, el Peregrino-Quetzalcóatl debe enfrentarse al última, que consiste en su descenso al inframundo (Mictlán) y el encuentro con los soberanos del Reino de la Muerte. Dicho descenso se produce en el siguiente capítulo ("Noche del volcán"). De nuevo, Fuentes nos presenta un ritual de muerte

\footnotetext{
${ }^{21}$ De acuerdo con sus prácticas rituales, cada año los nahuas elegían a un hombre que personificaba a Tezcatlipoca. El escogido disfrutaba de un año de placer, tras el cual era sacrificado al dios durante el día de sus celebraciones (Robelo 544-45).
} 
y resurrección representado, dentro de la geografía simbólica de la novela, por el descenso y posterior ascenso del personaje. Para ser exactos, el descenso al inframundo constituye la "tercera caída" del Peregrino, evocando así el aspecto cristológico y mesiánico de la figura de Quetzalcóatl que nos ofrecen algunos de los cronistas misioneros.

Para la narración del descenso del Peregrino al inframundo, Fuentes recurre a una de las leyendas que describen la creación del hombre y la participación de Quetzalcóatl como demiurgo. La Leyenda de los soles (1558) cuenta como los dioses, reunidos en Teotihuacán, comprendieron la necesidad de crear una nueva especie humana. Para ello encomendaron a Quetzalcóatl la tarea de descender al Mictlán en busca de los huesos que crearan esta nueva raza. Una vez allí, Quetzalcóatl, con la ayuda de su doble o nahual, superó las pruebas a que le sometieron el Señor y la Señora del Reino de la Muerte y escapó con los huesos a Tamoanchan donde, al regarlos con la sangre de su miembro viril, les infundió la vida.

Al margen de algunos detalles, la relación de Fuentes sigue en lo sustancial la de la leyenda mencionada. La diferencia principal, sin embargo, estriba en que La leyenda de los soles describe la creación del hombre del quinto sol, es decir, el hombre de la era actual, mientras que los huesos que rescata el Peregrino dan lugar a los primeros mestizos del Nuevo Mundo. ${ }^{22} \mathrm{Al}$ mojar los huesos con sus lágrimas, aquellos se transforman en diez hombres y diez mujeres que corren junto al Peregrino y que son descritos como "recién nacidos" que hablan español "con un acento más dulce" (456). Nos encontramos aquí frente a una nueva reescritura de la cosmogonía nahua que le permite a Fuentes dar expresión al mito fundacional del mestizaje. El mestizaje es así el resultado de lo contrario de lo que fue, es decir, no el fruto de la violencia, sino del amor. En lugar del padre cruel, Cortés, Fuentes concede al Nuevo Mundo un padre bondadoso, Quetzalcóatl. La estrategia es la misma que articula el Teatro de la Memoria de Valerio Camillo y, por extensión, Terra Nostra: mostrar aquello que pudo haber sido y no fue. En la tercera parte de Terra Nostra ("El otro mundo"), el propio Camillo describe su Teatro en términos que nos ayudan a comprender tanto el uso que Fuentes hace de la historia como su concepto de la utopía textual que propone en su obra:

Las imágenes de mi teatro integran todas las posibilidades del pasado, pero también presentan todas las oportunidades del futuro, pues sabiendo lo que fue, sabremos lo que clama por ser: cuanto no ha sido ... es un hecho latente, que espera su momento para su segunda oportunidad, la ocasión de vivir otra vida. La historia sólo se repite porque desconocemos la otra posibilidad de cada hecho histórico: lo que ese hecho pudo haber sido y no fue. Conociéndola, podemos asegurar que la historia no se repita; que sea la otra posibilidad la que por primera vez ocurra. El universo alcanzaría su verdadero equilibrio (567).

${ }^{22}$ Como hemos visto anteriormente, Fuentes fusiona el mito de la creación del quinto sol con el de la creación del nuevo hombre a través de la leyenda del sacrificio del dios leproso. Esto le permite establecer un vínculo más directo entre el origen del mestizaje y el valor utópico asociado a la figura de Quetzalcóatl. 
La finalidad de estas grandes maquinarias utópicas (el Teatro de la Memoria de Camillo y Terra Nostra de Fuentes) es mostrar una salida al fatalismo de la historia, una alternativa en la que los hispanoamericanos sean los forjadores de su propio destino. ${ }^{23}$

Al patrón mítico ofrecido por las narrativas sobre Quetzalcóatl "El mundo nuevo" superpone el de la épica de la conquista. A la utopía Fuentes enfrenta el apocalipsis. Hemos visto como ambos elementos (mitos prehispánicos y conquista) aparecen entremezclados en algunas de las versiones comentadas. Los dos componentes de este doble hilo conductor mantienen un diálogo permanente a través de la leyenda del regreso de Quetzalcóatl y su identificación con Cortés. Así, por ejemplo, la mencionada estructura de pruebas iniciáticas sirve también en la obra de Fuentes un propósito más mundano o secular. A través de ellas, Fuentes describe simultáneamente la astucia racional del conquistador enfrentado a un mundo sobrenatural. Esta idea aparecerá confirmada a medida que vayamos reconociendo en muchos de los movimientos y reacciones del Peregrino los de Cortés, tal y como fueran descritos por Bernal Díaz en su Historia verdadera o Fray Bernardino de Sahagún en su Historia General.

En todo lo concerniente a la supuesta identificación entre Cortés y Quetzalcóatl Fuentes parece seguir de cerca la versión de Sahagún. Mediante la polivalencia y plurifuncionalidad que otorga a la figura del Peregrino, Fuentes lleva aún más lejos tal superposición entre el regreso de Quetzalcóatl y la conquista de la Nueva España. Sería ingenuo establecer una mera identificación Peregrino-Quetzalcóatl. En el personaje central de "El mundo nuevo" se perciben igualmente otras muchas personalidades que nunca llegan a dominar por completo. Así, por ejemplo, conviven en él Quetzalcóatl y su contrario, Tezcatlipoca. También veíamos al comienzo de este apartado como se sumaban a su figura las representaciones de Pedro Serrano o Cabeza de Vaca. Desde los primeros contactos con los nativos del continente, empieza a tejerse, asimismo, una amplia red de referencias que nos mueve a asociar la figura del Peregrino con la de Cortés-Quetzalcóatl. En numerosas ocasiones es recibido con palabras tales como "Has regresado, hermano. Has llegado a tu casa. Ocupa en ella tu lugar", ${ }^{24}$

En el segmento titulado "Día de la laguna" se describe la marcha del Peregrino sobre México junto al grupo de muchachos y muchachas mestizos que fueron creados por él

\footnotetext{
${ }^{23}$ En el "Prólogo del autor" a Todos los gatos, Fuentes especifica esta empresa histórica en el México contemporáneo y dentro del marco de la lucha anticolonialista: "Corresponderá al nuevo mundo mestizo - a los hijos de la Malinche-inventar nuevos proyectos históricos y la lucha, hasta nuestros días, será entre colonizadores y descolonizadores. Mientras México no liquide el colonialismo, tanto el extranjero como el que algunos mexicanos ejercen contra millones de mexicanos, la conquista seguirá siendo nuestro trauma y pesadilla históricos: la seña de una fatalidad insuperable y de una voluntad frustrada" (1164).

${ }^{24}$ Algunos de los momentos de la novela en que se da la bienvenida al Peregrino en tales términos son: encuentro con el anciano de las memorias $(393,401)$, encuentro con la vieja que le acoge tras su primer día de viaje en busca de la señora de las mariposas (416), recibimiento de los indígenas tras su caída y renacimiento del cenote (422), encuentro con los reyes del inframundo (450), saludo de los primeros jóvenes mestizos (456), bienvenida de Moctezuma (463), y reencuentro final con el anciano del pueblo de la selva en la plaza de Tlatelolco (482).
} 
durante su visita al inframundo. Esta nueva conquista de México, ahora pacífica, se corresponde a menudo con la relación de Bernal Díaz en su Historia verdadera. La figura del Peregrino en cuanto narrador, por tanto, incorporaría también la personalidad del conquistador y cronista español. En concreto el texto reproduce el pasaje en que Bernal muestra su admiración ante el panorama del Valle de México. ${ }^{25}$ Incluso a nivel sintáctico algunos episodios como la descripción del mercado de Tlatelolco parecen seguir la tortuosa sintaxis de Bernal Díaz, con sus frases interminables unidas por gran cantidad de conjunciones copulativas (Terra Nostra 460; Historia 171-72). ${ }^{26}$

En "El mundo nuevo" la llegada del Peregrino-Quetzalcóatl-Cortés al Valle de México coincide con la aparición de "portentos" o "funestos signos" que siguen literalmente aquellos descritos por Sahagún en su Historia General. A medida que el Peregrino se aproxima a México-Tenochtitlan surge una llama de fuego que se eleva hasta el cielo como una pirámide de luz (primer presagio en Sahagún), hierven las aguas de la laguna (quinto presagio), cae un gran fuego o cometa desde el sol del que nacen tres más (cuarto), caen rayos sin truenos que incendian los techos de los edificios (tercero), una mujer surgida de la niebla llora por el destino de su ciudad y de sus hijos (sexto), monstruos bicéfalos anuncian el fin del mundo (octavo), y por último, en la laguna encuentran un ave muerta en cuya cabeza un espejo proyecta imágenes de la conquista (séptimo). En el encuentro del Peregrino con Moctezuma (a quien no se menciona por el nombre) se repiten las palabras que la Historia de Sahagún pone en boca del soberano azteca cuando da la bienvenida a Cortés: "--Señor nuestro: te has fatigado, te has dado cansancio; ya a la tierra tú has llegado. Has arribado a tu ciudad: México. Aquí has venido a sentarte en tu trono. Oh, por breve tiempo te lo conservamos" (Terra Nostra 463).

En la descripción del tiempo que el Peregrino-Cortés pasa en la capital azteca Fuentes se vale de la información que ofrecen: el propio Cortés en sus Cartas, Gómara y Bernal Díaz. La narración de la caída de Quetzalcóatl se entremezcla, asimismo, con estos sucesos. Las razones que Fuentes aducía para la caída del héroe (embriaguezy fornicación) se repiten aquí de forma original. En lugar de ser Tezcatlipoca el que engaña a Quetzalcóatl, es la Señora de las Mariposas en su tercera aparición, esta vez como anciana decrépita, quien le ofrece una bebida al héroe. En lugar del incesto que Fuentes ve en los Anales, en la novela la transgresión sexual se manifiesta en una primera instancia mediante la violación de la anciana. Sin embargo, poco después, el Peregrino en su faceta de Quetzalcóatl es acusado por el príncipe cojitranco (Moctezuma-Tezcatlipoca) de embriaguez e incesto, lo que hace pensar que el aparente encuentro con la Señora de las Mariposas pudiera haber sido un hechizo o una nueva trampa del dios-mago Tezcatlipoca. Las palabras que pronuncia este último repiten la versión del mito de la caída de Quetzalcóatl que propone Fuentes en sus ensayos y obras de teatro: “... véanlo; vean al joven señor del amor y de la paz; vean al creador de los hombres; vean al educador manso y caritativo; vean al enemigo del sacrificio

\footnotetext{
${ }^{25}$ Este mismo pasaje en el que Bernal Díaz compara su visión de México con las maravillas que se cuentan en los libros de caballerías lo reproduce aún más literalmente en Ceremonias del alba (7172).

${ }^{26}$ Sobre la influencia de Bernal Díaz en "El mundo nuevo", véase Verónica Cortínez. Fuentes ha discutido a menudo en sus ensayos el componente novelístico en la obra de Bernal Díaz. Véase, por ejemplo, "La épica vacilante de Bernal Díaz del Castillo" (Valiente mundo 72-96).
} 
y de la guerra; vean caído al creador; vean su vergüenza desnuda y borracha; véanle embriagado, recostado con su propia hermana ..." (473).

Pero la razón más inmediata de la huida del Peregrino no es la embriaguez y el incesto sino otro elemento que se encuentra también en la versión que Fuentes propone del mito: el terror producido ante la visión de una imagen especular. A la pregunta que el Peregrino hace a Tezcatlipoca sobre aquellos días olvidados de su viaje por tierras mexicanas, el diosmago le da como respuesta la vara de espejos de Xipe Totec. En cada uno de tales espejos se muestra una imagen de muerte en la que el Peregrino es el protagonista. Estas imágenes aluden a la destrucción general perpetrada por los conquistadores y a episodios específicos, protagonizados tanto por Cortés y Pedro de Alvarado en la conquista de la Nueva España, como por el Peregrino en Terra Nostra. El Peregrino cree que eso fue lo que hizo durante los días olvidados pero Tezcatlipoca le señala que "los espejos de esta vara miran hacia el futuro" (479), implicando así tanto un pasado de desolación como una profecía de destrucción para México. Tales augurios se cumplen cuando en su huida el Peregrino es testigo de una terrible matanza, suceso en cuya descripción se mezclan la memoria del asesinato en masa ordenado por Pedro de Alvarado en el Templo Mayor de la capital azteca y la premonición de la futura masacre de Tlatelolco en 1968, durante la administración de Díaz Ordaz.

En el mismo escenario de tal masacre tiene lugar, momentos antes, un suceso de capital importancia para el tema que estamos analizando: el Peregrino encuentra por última vez al anciano de las memorias, quien lo recibe con las palabras habituales, aunque con un leve cambio: "Sé muy bienvenido, mi hermano. Te hemos esperado. Te esperaremos siempre" (482). La última frase alude a la necesidad de creencia permanente en este mito como fuente de esperanza utópica, sugiriendo además el carácter inextinguible del mismo: el Peregrino es esperado para cumplir la promesa de Quetzalcóatl, pero al mismo tiempo que la cumple la destruye, escapa y se espera su regreso de nuevo. El mensaje críptico del anciano alude también a una nueva faceta de Quetzalcóatl a la que solo hemos hecho mención ocasionalmente y que demuestra tener una importancia capital para Fuentes. El Peregrino es reconocido como Quetzalcóatl en su papel de líder cultural y político, patrón de las artes, guardián de la memoria y abanderado del cambio. De hecho, las palabras del anciano resumen el papel martirológico y mesiánico que Fuentes atribuye al intelectual y, en particular, al escritor latinoamericano a lo largo de la historia del continente: "Tu destino es ser perseguido. Luchar. Ser derrotado. Renacer de tu derrota. Regresar. Hablar. Recordarles lo olvidado a todos. Reinar por un instante. Ser derrotado de nuevo por las fuerzas del mundo. Huir. Regresar. Recordar. Un trabajo sin fin. El más doloroso de todos. Libertad es el nombre de tu tarea. Un nombre con muchos hombres" (484). ${ }^{27}$

\footnotetext{
${ }^{27}$ Compárese esta descripción del Peregrino con la que Fuentes hace del escritor latinoamericano en su ensayo "La tradición literaria latinoamericana": "Todo escritor nombra al mundo; pero el escritor latinoamericano está poseído del pánico urgente del descubridor: si yo no nombro, nadie lo hará; si yo no escribo, todo será olvidado; si todo es olvidado, dejaremos de ser" (26). El carácter mesiánico atribuido al escritor reaparece constantemente en la obra de Fuentes: "Nuestras sociedades civiles han sido sumamente débiles: el escritor es elegido en silencio para darles voz". Sobre este mismo tema véanse también "Discurso inaugural" (13), Obras completas (85-98), Valiente mundo (285-95) y Geografia de la novela (25).
} 
Tanto el potencial redentor del intelectual como el poder transformador de la palabra no son contemplados como un fenómeno moderno, sino dentro de una tradición que, según Fuentes, se remonta al mundo indígena. La soflama política del tlamatini es seguida de su apasionada exaltación de la cara oculta del mundo azteca, no ya el lado cruel del imperio, sino el mundo de los artesanos y poetas que se dan cita en la plaza de Tlatelolco (484). En este mismo universo de la plaza, lugar de encuentro e intercambio bajtinianos, el Peregrino escucha unas voces de poetas que subrayan esta misma persistencia del escritor en su escritura:

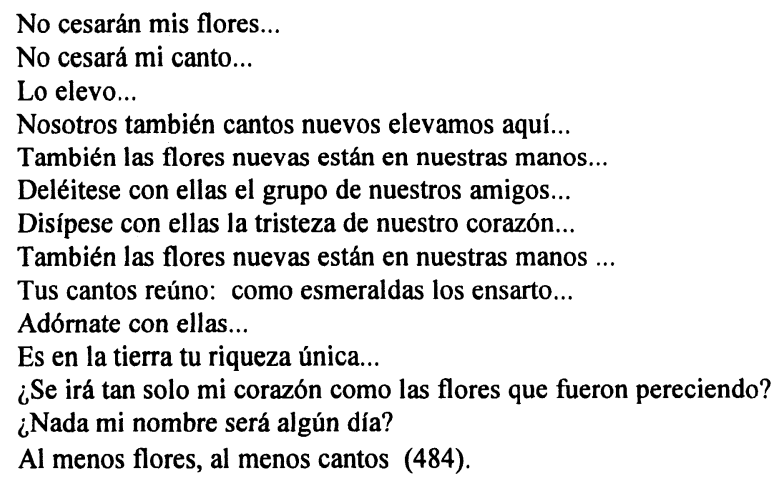

Lo que se presenta como una unidad orgánica es, en realidad, un conseguido collage de poemas que en su origen trataban motivos recurrentes dentro de la poesía náhuatl, especialmente la transitoriedad de nuestro paso por la tierra y la necesidad de disfrutar de nuestras vidas mortales. Todos los versos proceden de diferentes poemas recogidos en el manuscrito del siglo XVI Cantares mexicanos. Una gran parte de tales poemas la constituyen las alabanzas y encomios que los poetas se hacían entre sí, lo cual cuadra a la perfección con el homenaje que Fuentes rinde a la figura del escritor en Terra Nostra. ${ }^{28}$ Los fragmentos citados en la novela son recitados por un grupo de poetas anónimos, sin que exista un emisor individual y definido. Se presentan como versos que el Peregrino escucha al azar en medio del ajetreo de la plaza de Tlatelolco. El origen múltiple de las voces que forman el poema contribuye a crear una impresión polifónica y democrática que Fuentes erige como propuesta utópica frente al poder despótico del "Señor de la Gran Voz" (el emperador azteca). Ante el discurso monológico del tirano, el autor de Terra Nostra presenta el valor transgresivo de una comunidad basada en la igualdad de la expresión:

${ }^{28}$ Una selección en español de este manuscrito aparece en Angel María Garibay, Historia de la literatura náhuatl. Los tres primeros versos están entresacados de un poema que Garibay atribuye al poeta-rey Nezahualcóyotl (I, 244). Los versos 4-7 son parte de un poema de Chalco en el que se canta la fugacidad de la vida y los cantos $(I, 184)$. Los versos 8-10 tienen su origen en la obra que otro poeta de Chalco dedica a un colega (I, 181). Finalmente, los últimos tres versos forman parte de un pieza que Garibay significativamente titula "Misión del poeta" (La literatura 67). 
"Diste la palabra a todos, hermano. Y por temor a la palabra de todos, tu enemigo se sentirá siempre amenazado" (485).

Sin embargo, la imagen que Fuentes presenta de la poesía azteca no parece ajustarse a la realidad histórica. Por un lado, en la cultura nahua la poesía no era precisamente una forma de expresión popular y democrática, o al menos no el sentido que atribuimos hoy día a tales conceptos, sino expresión de los valores militares de la nobleza azteca. ${ }^{29}$ Por otra parte, en la poesía náhuatl el poema es comparado recurrentemente con la flor, tanto por su belleza como por su carácter efímero. En la selección que hace Fuentes, si bien se mantiene esta equiparación flor-poema, se enfrenta lo transitorio de la existencia con la permanencia del arte. Compárense los tres últimos versos citados de Terra Nostra con el poema náhuatl que Garibay llama sugestivamente "Misión del poeta":

\author{
De modo igual me iré \\ que las flores que fueron pereciendo, \\ ¡Nada será mi renombre algún día! \\ ¡Nada será mi fama en la tierra! \\ ¡Al menos flores, al menos cantos! (Garibay, La literatura 67).
}

Los cambios que Fuentes introduce en la puntuación de los versos y el contexto en el que se incluyen modifican el sentido de la versión de Garibay. Lo que en el texto original parece ser una aceptación de la fugacidad de todo lo terrestre, tanto la fama y el renombre como lo más bello representado por las flores y la poesía de transmisión oral, se convierte en el texto de Fuentes en una utópica defensa del valor permanente del arte y del poder transformador de la palabra. Este valor mesiánico que Fuentes atribuye al mundo de la cultura en general y al hombre de creación en particular tiene un claro referente intelectual en la obra Miguel León Portilla. ${ }^{30}$ Desde su ya clásico ensayo La filosofia náhuatl estudiada en sus fuentes (1956), la labor investigadora de León Portilla ha estado orientada a presentar el lado humanista de las civilizaciones prehispánicas. Frente a la crueldad militar de los aztecas, León Portilla presenta el refinamiento de sus prácticas culturales. A lo largo de su obra incide en la necesidad de establecer una separación entre los ámbitos político y cultural

\footnotetext{
${ }^{29}$ La poesía azteca difícilmente podía ser vista como una amenaza por la clase dominante, ya que constituía uno de los vehículos de expresión privilegiados de esa misma clase. En respuesta a la perspectiva humanista de Miguel León Portilla, David Damrosch ha señalado como no sólo no existe una contradicción entre el refinado esteticismo de la poesía mesoamericana y las crueles prácticas del imperio azteca, sino que tal esteticismo era parte intrínseca de la lógica política del imperio (101). De hecho, una gran parte de estos poemas asocian la belleza del mundo natural con las artes militares y el sacrificio humano. La guerra es a menudo descrita como un acto artístico en la que el guerrero desempeña el papel del poeta (105). Damrosch añade, además, la dificultad de separar elementos auténticamente indígenas de aquellos que hubieran podido recibirse de los europeos como consecuencia del proceso de transculturación llevado a cabo durante el siglo XVI, momento en el que se compusieron la mayoría de estos poemas (102).

${ }^{30}$ En El espejo enterrado (394), Fuentes alude a las obras de León Portilla como "las mejores investigaciones modernas del mundo tolteca-azteca" y da una larga relación bibliográfica de las mismas.
} 
de su sociedad: "coexistieron así ... dos concepciones distintas y aún tal vez opuestas, del universo y la vida" (265). En la visión humanista e idealizada de León Portilla, los tlamatinime (síntesis de lo que en la tradición occidental consideraríamos como filósofos y poetas) representaban la conciencia moral del mundo nahua y constituían el vínculo más directo con la figura de Quetzalcóatl como patrón del saber (265). Esta idea aparece recurrentemente en "El mundo nuevo", donde a través del anciano de las memorias Fuentes comunica su nostalgia por un paraíso cultural perdido (el reinado mítico de Quetzalcóatl) en el que el mundo de la filosofía, el arte y la poesía ocupaban un lugar predominante en la sociedad.

Dentro del marco ofrecido por las palabras del anciano, la posibilidad de restaurar esta armonía original se asocia con la llegada del Peregrino a las costas del Nuevo Mundo, marco por excelencia de aventuras utópicas: "La libertad fue la orilla que el hombre primero pisó. Paraíso fue el nombre de esa libertad. La perdimos palmo a palmo. La ganaremos palmo a palmo" (485). El discurso del anciano de las memorias se cierra con una invocación a la lucha por la transformación social, lucha que es contemplada como utópica, pero no por ello menos importante. El fin de su mensaje coincide con el estruendo de la masacre de Tlatelolco y la huida del Peregrino. Esta última es presentada en términos que evocan la descripción que hace Sahagún de la huida de Quetzalcóatl. Como el héroe-dios en la versión de Sahagún, el Peregrino desaparece en el horizonte rumbo hacia Levante en una barca de serpientes. Venus brilla al final de su viaje (492). ${ }^{31}$

Aunque libremente, el relato del Peregrino sigue (tal y como hemos podido comprobar) el patrón arquetípico en siete etapas que Nicholson deduce de las narrativas sobre Topiltzin Quetzalcóatl: 1) nacimiento, 2) juventud, 3) entronización, 4) apogeo, 5) caída, 6) huida, y 7) muerte o desaparición. 1) El despertar del Peregrino en el Nuevo Mundo funciona a modo de nacimiento (el Peregrino desconoce su origen). 2) Su iniciación en la madurez y consiguiente aceptación en la comunidad se produce en compañía del pueblo de la selva, con el que aprende a compartir su forma de vida y sus costumbres, siendo finalmente aceptado como un miembro más del grupo. 3) Tras la muerte del anciano guardián de la memoria, el Peregrino ocupa el lugar de aquél (si bien tal entronización es presentada en términos ambiguos); 4) el apogeo del Peregrino se produciría tras la superación de las siete pruebas que culminan con su descenso al inframundo, su creación de una nueva raza y su marcha victoriosa sobre México-Tenochtitlan. 5) La caída del personaje se produce, al igual que en la historia de Quetzalcóatl, como resultado de las tentaciones de Tezcatlipoca. 6) A su caída le sigue la huida narrada en el segmento narrativo "Día de la fuga". 7) La última etapa en el recorrido del Peregrino consiste en su desaparición en el mar, rumbo a levante y bajo el signo de Venus.

\footnotetext{
${ }^{31}$ Fuentes fusiona, por tanto, las dos versiones existentes del fin de Quetzalcóatl. En los Anales, tras su autoinmolación, el corazón de Quetzalcóatl se transforma en el planeta Venus. En la Historia General el héroe-Dios huye por mar hacia Levante en una barcaza de serpientes, no sin antes haber anunciado su regreso.
} 
Los dos problemas principales que implica el análisis textual de "El Mundo Nuevo" son el fragmentarismo de la mitología prehispánica y la ambivalencia con que Fuentes caracteriza a los personajes. En el ámbito de la religión azteca es difícil llegar a conclusiones definitivas. La forma fragmentaria en que los mitos han llegado hasta nosotros debe atribuirse principalmente a la oralidad de la cultura nahua, que nos impide el acceso a fuentes originales, libres de los efectos transculturadores de la conquista. El problema se hace más agudo en el rastreo de la saga de Quetzalcóatl, una figura cuyas manifestaciones son, cuanto menos, proteicas, y que ha cobrado valores diferentes en función de los grupos de interés que se sirvieron de ella. El valor funcional más importante que se desprende de nuestro análisis del mito es, sin duda, su poder explicatorio y legitimador. Como han expresado desde perspectivas diferentes Roland Barthes (142-43), Georges Dumézil (50), Alfredo López Austin (Los mitos 390-91) y Paul Ricoeur (73), el mito otorga una justificación natural a las aspiraciones de una comunidad; convierte lo contingente en eterno. En el caso de Quetzalcóatl, actúa además como suplemento de la historia, cubriendo de este modo un espacio que permanecía vacío en el pensamiento teleológico de españoles e indígenas. Todas las partes envueltas en la empresa de la conquista podían explicar a la luz del mito de Quetzalcóatl, algo que de otro modo les resultaba inconcebible: la existencia de todo un universo diferente. Para los conquistadores la leyenda del regreso de Quetzalcóatl favorecía sus pretensiones de legitimación jurídica como señores naturales del Nuevo Mundo, mientras que para muchos de los misioneros implicaba, o la idea fantástica de una evangelización anterior a la conquista, o bien el reflejo de su propia mentalidad apocalíptica (un anuncio, por ejemplo, del reino milenario que los franciscanos pretendían materializar en el Nuevo Mundo). Para muchos de los vencidos justificaba su derrota, la cual no se atribuía así a la falta de valor o de capacidad militar, sino a la fatalidad del destino. Para aquellos otros enfrentados a los tenochcas (como los habitantes de Tlatelolco que ayudaron a Sahagún en la confección de su Historia General) permitía infravalorar la figura de Moctezuma al presentarlo como un soberano débil e incapaz.

La obra de Fuentes responde a un impulso legitimador semejante. En su uso del mito de Quetzalcóatl, Fuentes construye una versión amalgamadora y global en la que se reúnen elementos del dios (Ehécatl) y del héroe (Topiltzin). ${ }^{32}$ A ello habría que añadir su collage abarcador de numerosas versiones del mito y la leyenda, favorecido por la flexibilidad consustancial al género novelístico. De todos los valores atribuidos a Quetzalcóatl, Fuentes muestra una preferencia especial por sus aspectos demiúrgico y cultural. El elemento de terror implicado en la figura de Ehécatl o los atributos bélicos que presentan muchas versiones de Topiltzin están ausentes en la versión de Fuentes. En cambio, se subraya el papel de Quetzalcóatl como dador de vida, héroe y líder cultural de su pueblo. Ambos aspectos de la figura de Quetzalcóatl encuentran una síntesis original en "El mundo nuevo"

\footnotetext{
${ }^{32}$ Fuentes basa su visión del mito fuertemente en la lectura de Séjourné (lectura de carácter místicosimbólico que muestra particular aversión a interpretaciones historicistas) y convierte a Quetzalcóatl en un compendio totalizador de la mitología nahua. Referencias a la obra de Séjourné pueden encontrarse en Tiempo mexicano (18) y El espejo enterrado (395).
} 
a través del valor mesiánico que Fuentes atribuye al escritor latinoamericano. Como hemos visto en su reinvención del mito, detrás de la figura de Quetzalcóatl no es difícil atisbar la del hombre de creación y, en el caso de México, la del escritor mestizo como abanderado del cambio cultural y político del país.

La visión de la conquista que se desprende de "El mundo nuevo" no es ajena a esta misma exaltación del mestizaje. Inspirado en la tradición utópica vasconceliana, Fuentes contempla la conquista como un fenómeno catastrófico del que, sin embargo, surgió algo positivo: la creación de un nueva civilización multiétnica y plural. En su tratamiento de los protagonistas de este momento histórico se siguen las pautas establecidas en Todos los gatos son pardos. Frente al poder de la voluntad de Cortés, Fuentes opone el poder de la fatalidad, representado en Moctezuma. Ambos son retratados negativamente. Cortés es caracterizado en su aspecto antiépico, de ahí que las fuentes a las que se recurre con más frecuencia sean no tanto Cortés mismo como Bernal Díaz y, especialmente, Sahagún. En el lado indígena, Moctezuma es presentado de forma muy marginal, hasta el punto de que no se le menciona directamente. El soberano azteca ostenta en la novela los atributos negativos de Tezcatlipoca, dios del cielo nocturno, de las guerras, encrucijadas y discordias. "El mundo nuevo" idealiza, en cambio, al pueblo llano, especialmente a las comunidades indígenas sometidas al yugo mexica, así como a los artistas y artesanos nahuas. Para ello Fuentes hace un uso libre de la obra de Sahagún, quien recoge la visión de algunos de los vencidos.

Este complejo maridaje de intertextos históricos, poéticos y mitológicas dentro de una narrativa autoconsciente es uno de los rasgos distintivos de la nueva novela histórica, teorizada desde perspectivas y en ámbitos diferentes por Brian McHale, Linda Hutcheon y Seymour Menton. ${ }^{33}$ En las obras de estos tres críticos se contempla la tendencia generalizada en la ficción histórica de nuestros días a socavar los postulados básicos de la novela histórica tradicional. Frente a las pretensiones objetivistas de la novela histórica realista, obras como las de Fuentes se caracterizan por una epistemología profundamente subjetiva que problematiza tanto el conocimiento histórico como el concepto de mímesis en todas las prácticas discursivas. ${ }^{34}$ En contra de aquellos que, como Lukács, negaban a la ficción un valor cognitivo específico, las nuevas formas de la narrativa histórica hacen de la novela un sistema de conocimiento que no sólo refleja, sino también configura, la realidad social (Hutcheon 1988:192). Desde este punto de vista, la obra histórica no consiste en la

\footnotetext{
${ }^{33}$ En Latin America's New Historical Novel (1993), Menton reconoce en Fuentes a uno de los pioneros que catapultaron esta nueva modalidad narrativa en Latinoamérica. Si bien las novelas históricas más recientes tienden a distanciarse de los proyectos enciclopédicos de las novelas del boom, las características generales de este nuevo género, de acuerdo con Menton (relativismo, distorsión de la historia, uso de personajes históricos famosos como protagonistas, metaficción, intertextualidad y dialogismo carnavalesco y heteroglótico), tienen su manifestación ejemplar en "El mundo nuevo". Hutcheon (1988:212; 1989:77) y McHale $(1987: 15-18,21,67,78,92-94,174,203)$ se valen igualmente de Terra Nostra para ejemplificar el revisionismo de la ficción postmodernista a nivel internacional.

${ }^{34}$ Recordemos que el teórico principal de la novela histórica tradicional, Georg Lukács, circunscribía la mímesis de la novela histórica a una epistemología realista: "the aesthetic illusion is only possible when the art reflects the total objective process of life with objective accuracy" (41). Sollo aquellas obras que replicaban la trayectoria de la historia tenían, según Lukács, un valor estético genuino.
} 
representación fiel de una realidad prelingüística ("el proceso objetivo total de la vida"), sino en un discurso fluctuante que reflexiona sobre el pasado desde el presente ideológicamente situado del escritor. Además de su papel problematizador de la verdad histórica oficial, el revisionismo de estas novelas tiene también un claro potencial democratizador. La apertura de un nuevo espacio para la producción de historias alternativas favorece el acceso al registro de los grupos secularmente marginados. Mediante versiones apócrifas y fantásticas, la nueva novela histórica suple, contradice o desplaza las versiones heredadas del pasado, ilumina las áreas oscuras del archivo y da voz a aquellos que habían sido excluídos del mismo (McHale 1987:90-91).

En última instancia la labor del nuevo novelista histórico no está orientada hacia el pasado sino hacia el porvenir. Según Fuentes, la novela es el espacio de lo posible, en el que partiendo de la revisión del pasado pueden ensayarse nuevos proyectos de cambio para el futuro. "El mundo nuevo" se ofrece precisamente como modelo de la gran empresa utópica que, según Fuentes, deben afrontar los latinoamericanos: la creación de una gran síntesis de su realidad profundamente heterogénea. A nivel literario, esta síntesis se manifestaría en formas abiertas y enciclopédicas que aspirarían a una difícil coexistencia de "todos los contrarios vistos simultáneamente desde todas las perspectivas posibles" (Cervantes 106). A nivel historiográfico, se busca igualmente integrar "todas las posibilidades del pasado" (Terra Nostra 567) en una visión heterodoxa del devenir. La "herejía histórica" resultante es el arma principal con que Fuentes se propone subvertir el discurso del poder manifestado en las visiones épicas del pasado. En este contexto, Fuentes reinventa tanto la épica nahua como la épica de la conquista, despojando a ambas de "su viejo significado unívoco" (Tiempo mexicano 20). Desposeídos de su función ritual precisa, los mitos prehispánicos adquieren una polivalencia significativa casi infinita, convirtiéndose en paradigmas de la obra abierta que Fuentes propone como ideal estético del arte de nuestro siglo. Privadas de su finalidad burocrática o evangelizadora, las crónicas de Indias reescriben, de la mano del novelista, el origen del mestizaje en Latinoamérica. Mito e historia se hermanan en la obra de Fuentes, no para repetir el pasado, sino para crear un mundo nuevo.

\section{BiBLIOGRAFIA}

Ainsa, Fernando. "La función de la utopía en la historia del pensamiento de América Latina". Memoria del XX Congreso de Literatura Iberoamericana. Budapest: Universidad Eötvös Lorand, 1982. 23-31.

Anglería, Pedro Mártir de. Décadas del Nuevo Mundo. Ed. Joaquín Torres Asensio. Buenos Aires: Bajel, 1944.

Barthes, Roland. Mythologies. New York: The Noonday P, 1972.

Benavente, Fray Toribio de (Motolinía). Memoriales o libro de las cosas de la Nueva España y de los naturales de ella. México: UNAM, 1971. Historia de los los indios de la Nueva España. Madrid: Castalia, 1989.

${ }^{35}$ En uno de sus últimos ensayos, Fuentes llega a proponer la novela como el vehículo que podría sustituir a las metanarrativas de la liberación agotadas en nuestro tiempo (Geografia 219). 
Carrasco, David. Quetzalcóatl and the Irony of the Empire. Chicago: Chicago University Press, 1982.

Caso, Alfonso. El pueblo del sol. México: FCE, 1953.

Colón, Cristóbal. Textos y documentos completos. Ed. Consuelo Valera. Madrid: Alianza, 1982.

Colón, Hernando. Historia del Almirante. Ed. Luis Arranz. Madrid: Historia 16, 1984.

Cortínez, Verónica. "Crónica, épica y novela: La Historia verdadera de la conquista de la Nueva España y "El mundo nuevo" de Terra Nostra". Revista Chilena de Literatura 38 (1991): 59-72.

Damrosch, David. "The Aesthetics of Conquest: Aztec Poetry Before and After Cortés". Representations 33 (Winter 1991): 101-120.

Díaz del Castillo, Bernal. Historia verdadera de la conquista de la Nueva España. Ed. Joaquín Ramírez Cabañas. México: Porrúa, 1983.

Dumézil, Georges. "Del mito a la historia". Historia y diversidad de las culturas. Eds. A. Al-Azmeh et al. Barcelona: Serbal, 1984.

Durán, Fray Diego. Historia de las Indias de Nueva España. México: Porrúa, 1967.

Elliott, J.H. "The Mental World of Hernán Cortés." Transactions of the Royal Historical Society. Vol 17. London: Offices of the Royal Historical Society, 1967. 41-58.

The Old World and the New, 1492-1650. Cambridge: Cambridge University Press, 1970.

Evans, J. Martin. America: The View From Europe. New York: W. W. Norton, 1979. Fernández, Adela. Diccionario ritual de voces Nahuas. México: Panorama, 1988.

Frankl, Victor. "Hernán Cortés y la tradición de las Siete Partidas: Un comentario jurídicohistórico a la llamada "Primera Carta de Relación" de Hernán Cortés". Revista de Historia de América 53-54 (Junio-Diciembre 1962): 9-74.

"Imperio particular e imperio universal en las Cartas de Relación de Hernán Cortés". Cuadernos Hispanoamericanos 163-164 (Julio-Diciembre 1963): 443-82.

Fuentes, Carlos. La nueva novela hispanoamericana. México: Joaquín Mortíz, 1969. Tiempo mexicano. México: Joaquín Mortiz, 1972.

Terra Nostra. México: Joaquín Mortiz, 1975.

Cervantes o la crítica de la lectura. México: Joaquín Mortíz, 1976.

"Discurso inaugural". Simposio Carlos Fuentes: Actas. Eds. Isaac Jack Lévy y Juan

Loveluck. Hispanic Studies 2 (1978): 3-19.

Todos los gatos son pardos. Obras completas. Vol. II. México: Aguilar, 1980.

1149-61.

"La tradición literaria latinoamericana". La obra de Carlos Fuentes: Una visión múltiple. Madrid: Pliegos, 1988. 19-27.

Valiente mundo nuevo: épica, utopia y mito en la novela hispanoamericana.

México: Fondo de Cultura Económica, 1990.

Ceremonias del alba. Madrid: Mondadori, 1991.

El espejo enterrado. México: Fondo de Cultura Económica, 1992.

Geografia de la novela. Madrid: Alfaguara, 1993.

Garibay, Angel María. Historia de la literatura náhuatl. México: Porrúa, 1954.

La literatura de los aztecas. México: Joaquín Mortiz, 1964. 
Gillespie, Susan D. The Aztec Kings: The Construction of Rulership in Ancient Mexico. Tucson: University of Arizona Press, 1989.

Hutcheon, Linda. A Poetics of Postmodernism. Londres y Nueva York: Routledge, 1988. The Politics of Postmodernism. London and New York: Routledge, 1989.

Imaz, Eugenio. Topía y Utopía. México: Tezontle, 1946.

Jonghe, M. Edouard de, ed. Histoyre du Méchique. Journal de la Société des Américanistes de Paris 2.2 (1905): 1-41.

Lafaye, Jacques. Quetzalcóatl and Guadalupe: The Formation of Mexican National Consciousness (1531-1813). Chicago: The University of Chicago Press, 1976.

Mesías, cruzadas, utopías: El judeo-cristianismo en las sociedades ibéricas. Trad. Juan José Utrilla. México: FCE, 1984.

León Portilla, Miguel. La filosofia náhuatl estudiada en sus fuentes. México: Instituto Indigenista Interamericano, 1956.

Visión de los vencidos: Relaciones indígenas de la conquista. México: UNAM, 1959.

Literaturas de Mesoamérica. México: SEP, 1984.

Lévi-Strauss, Claude. Le Pensée sauvage. Paris: Plon, 1962.

López Austin, Alfredo. Hombre-Dios: Religión y política en el mundo náhuatl. México: UNAM, 1973.

Los mitos del tlacuache: caminos de la mitología mesoamericana. México: Alianza Editorial Mexicana, 1990.

López de Gómara, Francisco. Historia general de las Indias y vida de Hernán Cortés. Caracas: Biblioteca Ayacucho, 1979.

Lukács, Georg. "Art and Objective Truth”. Writer and Critic and Other Essays. Ed. y trad. Arthur D. Khan. New York: Grosser \& Dunlap, Universal Library, 1971. 25-60.

McHale, Brian. Postmodernist Fiction. New York and London: Methuen, 1987.

Mendieta, Fray Gerónimo de. Historia eclesiástica indiana. México: Porrúa, 1971.

Menton, Seymour. Latin America's New Historical Novel. Austin: University of Texas Press, 1993.

Muñoz Camargo, Diego. Historia de Tlaxcala. Guadalajara: Edmundo Aviña Levy, 1966. Murray, Frederic W. "The Image of Utopia as a Conceptual Determinant in the Structural Development of Spanish American Culture". Imagination, Emblems and Expressions: Essays on Latin American, Caribbean, and Continental Culture and Identity. Ed. Helen Ryan-Ranson. Bowling Green, OH: Bowling Green State University Press, 1993. 29-39.

Nicholson, H.B. "Topiltzin Quetzalcóatl of Tollan: A Problem in Mesoamerican Ethnohistory". Ph.D. Diss., Harvard University, Cambridge, 1957.

"Ehécatl Quetzalcóatl vs. Topiltzin Quetzalcóatl: A Problem in Mesoamerican Religion and History”. En Actes du XLII Congrès International des Américanistes, Paris. vol. VI (2-9 September 1976): 35-47.

Núñez Cabeza de Vaca, Alvar. Naufragios. Ed. Trinidad Barrera. Madrid: Alianza, 1985. Olmos, Andrés de. Historia de los mexicanos por sus pinturas. Teogonia e historia de los mexicanos: Tres opúsculos del siglo XVI. México: Porrúa, 1965.

Pagden, Anthony, ed. Letters from Mexico. New Haven: Yale University Press, 1986. 
Pérez de Oliva, Hernán. Historia de la invención de las Indias. José Juan Arroum. Bogotá: Instituto Caro y Cuervo, 1965.

Phelan, John Leddy. The Millennial Kingdom of the Franciscans in the New World. Berkeley: University of California Press, 1970.

Quiñones Keber, Eloise. "From Tollan to Tlapallan: The Tale of Topiltzin Quetzalcóatl in the Codex Vaticanus A". Latin American Indian Literatures Journal 3.1 (1987): 7694.

"The Aztec Image of Topiltzin Quetzalcóatl". Smoke and Mist: Mesoamerican Studies in Memory of Thelma D. Sullivan. Eds. J. Kathryn Josserand y Karen Dakin. Oxford: BAR Iternational Series 402, 1988. 329-43.

Ricoeur, Paul. "Myth and History". The Encyclopedia or Religion. Ed. Mircea Eliade, vol. 10. New York: MacMillan, 1987. 273-82.

Robelo, Cecilio A. Diccionario de mitología nahua. México: Porrúa, 1982.

Sahagún, Bernardino de. Historia general de las cosas de Nueva España. Ed. Angel María Garibay. México: Porrúa, 1956.

Sanford, Charles L. The Quest for Paradise: Europe and the American Moral Imagination. Urbana: University of Illinois Press, 1961.

Séjourné, Laurette. Burning Water: Thought and Religion in Ancient Mexico. Berkeley: Shambhala, 1976.

Stenzel, Werner. Quetzalcóatl de Tula: Mitogénesis de una leyenda postcortesiana. Nuevo León: Facultad de Filosofía y Letras, 1991.

Vega, Inca Garcilaso de la. Comentarios reales. México: Porrúa, 1990.

Vespucio, Américo. El nuevo mundo: Cartas relativas a sus viajes y descubrimientos. Ed. R. Levillier. Buenos Aires: Nova, 1951.

Zea, Leopoldo. El pensamiento latinoamericano. México: Pormaca, 1965. 